\title{
Evidence for the equal resilience of Triodia spp. (Poaceae), from different functional groups, to frequent fire dating back to the late Pleistocene
}

\author{
G Armstrong \\ School of Environmental Research, Charles Darwin University, Darwin, Northern Territory, Australia
}

\begin{abstract}
Species with different regenerative responses to fire are hypothesised to coexist by utilising the different temporal and spatial niche opportunities created by the stochasticity of the fire regime. This is strongly supported by observations of instability of species' presence and abundance at the local scale while these are stable at the community scale. However, observations of species coexistence in fire-prone communities are limited to several decades only. To improve the robustness of this hypothesis, coalescent analysis, using chloroplast microsatellites, was undertaken on three sympatric species of Triodia from different functional groups in the fire-prone Kimberley region of Western Australia. The results inferred that
\end{abstract}

T. bitextura, an obligate resprouter, Triodia sp., an obligate seeder, and $T$. epactia, a facultative resprouter, had mean $T_{\text {mrca }}$ values of $65 \mathrm{k}, 40 \mathrm{k}$ and $111 \mathrm{k}$ generations, respectively. Using a mutation rate of $3.2 \times 10^{-5}$ and a generation time of 5 years gave $T_{\text {mrca }}$ values of $436 \mathrm{k}, 203 \mathrm{k}$ and $556 \mathrm{k}$ years, respectively. These results provide evidence for the coexistence of these species to the same fire regime dating back to the late Pleistocene. It also demonstrates the long-term resilience of an obligate seeder, Triodia sp., in a frequently burnt environment at the community scale.

Heredity (2011) 107, 558-564; doi:10.1038/hdy.2011.42; published online 15 June 2011

Keywords: fire; coexistence; Pleistocene; obligate seeder; obligate resprouter; facultative resprouter

\section{Introduction}

Plant functional groups are defined by a common set of physiological or phenological responses to environmental conditions or disturbances (Hooper and Vitousek, 1997). Applicable over a range of scales, the concept distinguishes annual from perennial, tree from herb or resprouter from obligate seeder, among many others. As such, using functional groups to classify plants provides a tractable means to study large-scale ecosystem processes (Ustin and Gamon, 2010). Plant functional groups defined by their regeneration strategies are hypothesised to differ in their resilience (sensu Holling, 1973) to the same fire regime. This is due to to differential allocation of resources to vegetative or sexual reproduction, which determines the probability of persisting through the fire return interval (Verdu, 2000). If the time taken to return to reproductive maturity is not achieved before the next fire event, populations will decline and suffer localised extinctions (Bradstock et al., 1996; Russell-Smith et al., 2002). Slow-growing obligate seeding species, those that rely entirely on seed germination after fire for regeneration, are considered to be the most vulnerable to this scenario (Hoffmann, 1998) and localised reductions and extinctions have been observed (Russell-Smith et al.,

Correspondence: G Armstrong, Fitzroy Basin Association, PO Box 139, Rockhampton, Queensland, Australia.

E-mail: graeme.armstrong@cdu.edu.au

Received 15 January 2011; revised 30 March 2011; accepted 27 April 2011; published online 15 June 2011
2002; Prior et al., 2007). However, the temporal and spatial scale and the reasons for which this occurs differ across plant structural groups meaning there is no single fire frequency that favours all species in a community (Pausas and Lloret, 2007). Tree species that require decades to reach maturity will be far more vulnerable than grasses to subdecadal fire intervals (Genries et al., 2009). The impact of the fire regime can therefore be species specific and variable across functional and structural groups. However, coexistence of both groups is widespread, with disturbance, particularly fire, hypothesised to mediate fluctuations in dominance of particular groups over time (Chesson, 2000; Clarke and Dorji, 2008).

The stable coexistence of species from different functional groups is possible owing to the covariance between environmental and competitive responses among species, which is known as the storage effect (Sears and Chesson, 2007). Empirical evidence for this has been shown across a range of fire-prone habitats on different continents for periods of up to several decades (Williams et al., 2003; Andersen et al., 2005; Thuiller et al., 2007). Thuiller et al. (2007) showed that although presence and abundance of species was highly unstable at the local scale, it was stable at the meta-community scale. These results help resolve contradictions that arise in regard to the vulnerability of particular functional groups to fire, that is, obligate seeders vs obligate resprouter, depending on the spatial and temporal scale of the observation. Given global changes in fire regimes across the world due to climate change and changes in 
land-use practices (Beerling and Osborne 2006; Shlisky et al., 2007), the ability to generalise and therefore predict long-term responses of functional groups to the fire regime is important for conservation-management practices. If the resilience of different functional groups in a community could be resolved over historical time periods, this would provide a much more robust analysis than studies spanning years or even decades.

Coalescence (Kingman, 1982) provides a technique for such an analysis, enabling the demography of a species to be inferred over times beyond that available from direct observation (see Kuhner, 2009 for a recent review). The ideal system to test the comparative historical resilience between plants from different functional groups would be in a region with high fire frequency using plants in which reproduction is initiated by fire.

The tropical savannas of northern Australia provide such a model system, as there are many plant species that rely on fire for regeneration and the average fire return interval is 5 years in lower-rainfall areas, increasing to biannual at lower latitudes, which have greater rainfall and therefore greater fuel accumulation (Felderhof and Gillieson, 2006). Taxa within Triodia provide ideal model species because they are reliant on fire for reproduction (Burbidge, 1943; Noble, 1989; Rice and Westoby, 1999) and encompass several functional groups, including obligate seeders (Casson and Fox, 1987), facultative resprouters and obligate resprouters (Wells, 1999). As with other species of obligate seeders, the resilience of obligate seeding Triodia spp. to short fire return intervals, as occurs in northern Australia, has been questioned (Rice and Westoby, 1999). However, as with all other predictions regarding the resilience of particular functional groups to particular fire regimes, the evidence is based on short-term observations. Here, I use coalescent analysis to determine the minimum time that three Triodia species, each from a different functional group, have persisted in the landscape where fire has been present for millennia.

\section{Materials and methods}

\section{Site details and sampling}

The study was carried out at Mornington Wildlife Sanctuary, in the south central Kimberley of northern Western Australia. The property, owned and managed by the Australian Wildlife Conservancy, covers 325000 ha within the savanna biome of the wet/dry tropics. It receives $600-800 \mathrm{~mm}$ of rain per year, with $90 \%$ falling during the summer months: November-April (http://www.bom. gov.au). The landscape is dominated by the quartzite sandstone escarpments of the Proterozoic King Leopold Sandstone and low basaltic hills and valleys of the Carson Volcanics (Geol. Survey WA, 1:250 000 Geol. Series). Fires in the area are both temporally and spatially stochastic at a local scale, owing to heterogeneity of stand structure, which is dependent on fuel loads, in turn being dependent on preceding rainfall and ignition from lightning strikes (Allan and Southgate, 2002). This is illustrated by fire scar mapping from remote-sensing data (Supplementary Appendix).

Leaf samples were collected from 16 individuals from each of the three species T. epactia, T. bitextura $\left(17^{\circ} 30.627^{\prime} \mathrm{S}, 126^{\circ} 6.514^{\prime} \mathrm{E}\right)$ and Triodia sp., $6 \mathrm{~km}$ away at

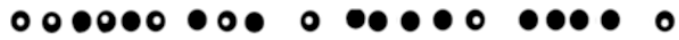

Figure 1 Representation of sequential sampling method. The black dots represent individual plants and leaf samples were collected from those with white dots. The sequence is counted as the number of individuals between samples: $0,1,1,1,1,4,4$ etc. See text for further details.

$\left(17^{\circ} 32.325^{\prime} \mathrm{S}, 126^{\circ} 9.452^{\prime} \mathrm{E}\right)$. T. epactia is a facultative resprouter with strong regrowth after fire plus some seed germination, $T$. bitextura is an obligate resprouter that has strong regrowth after fire, produces ramets and has virtually no seed production, and Triodia sp. is an obligate seeder in which all adults die during fire with total regeneration from the seed bank (unpublished data). Seeds are observed to be dispersed by both wind and surface water during rain events in the wet season.

Plants were sampled along a transect of exponentially increasing inter-plant distances in an attempt to capture potentially autocorrelated samples for which the scale was unknown. Plants were sampled, in the first half of the transect, not by fixed distances, but by the number of individuals between those sampled, following the sequence; $0,1,1,1,1,4,4,4,8,8,16,16$, with the numbers being the number of plants between those sampled (Figure 1). This was done because plants grow in a labyrinthine pattern with bare ground separating individual 'hummocks' at varying distances (Figure 4). This means any potential spatial autocorrelation would not be based on regular distances, but by the number of individuals that separate those that are sampled. Sampling in the latter half of the transect used predetermined fixed distances at 50,50, 100 and $100 \mathrm{~m}$ because many individuals are included at this scale. Total distances of each transect were therefore slightly different, being $372 \mathrm{~m}$ for T. bitextura, $366 \mathrm{~m}$ for T. epactia and $383 \mathrm{~m}$ for Triodia $\mathrm{sp}$.

Leaf tissue samples, approximately $3 \mathrm{~cm}$ long, were stored in Eppendorf tubes in a refrigerator until analysis, whereupon samples were ground in liquid nitrogen and total DNA extracted using DNneasy Plant Mini Kit (Qiagen, Valencia, CA, USA) following the manufacturer's protocol. Chloroplast microsatellites were chosen to determine demographic histories as they are nonrecombining, haploid and effectively uni-parentally inherited (Birky, 1995), providing direct evidence of a lineage. The availability of 'universal primers' for highly conserved primer sites on either side of polymorphic repeat regions has made such analyses possible (Provan et al., 2004; McGrath et al., 2006).

\section{Microsatellites}

A total of 10 non-coding microsatellites were tested from those developed by McGrath et al. (2006) and Provan et al. (2004), from which only four, trnK, atpI/atpH, atpB/rbcL and TeaSSR4 (23S-5S internal transcribed spacer), were able to be amplified. Only the last three had polymorphic alleles and were used in the analysis. PCR amplification was performed with the following parameters for atpI and atpB: initial denaturation of $72{ }^{\circ} \mathrm{C}$ for $3 \mathrm{~min}$ followed by 35 cycles of $94^{\circ} \mathrm{C}$ for $1 \mathrm{~min}$, $56^{\circ} \mathrm{C}$ for $1 \mathrm{~min}$ and $72{ }^{\circ} \mathrm{C}$ for $1 \mathrm{~min}$ with a final extension of $72^{\circ} \mathrm{C}$ for $5 \mathrm{~min}$. The parameters for Tea 4 were $95^{\circ} \mathrm{C}$ for $1 \mathrm{~min}$ with 35 cycles of $95^{\circ} \mathrm{C}$ for $1 \mathrm{~min}, 60^{\circ} \mathrm{C}$ for $1 \mathrm{~min}$ 
and $72{ }^{\circ} \mathrm{C}$ for $1 \mathrm{~min}$ with a final extension of $72{ }^{\circ} \mathrm{C}$ for $10 \mathrm{~min}$. Total genomic samples were amplified in a $15-\mu \mathrm{l}$ PCR reaction containing $1 \mu \mathrm{l}$ genomic DNA, $1.5 \mu \mathrm{l} 10 \times$ Gold buffer, $2.5 \mathrm{mM} \mathrm{MgCl}_{2}, 0.5 \mathrm{U}$ Ampli Taq Gold, $10 \mu \mathrm{M}$ fluorescence-labelled forward primer and $10 \mu \mathrm{M}$ reverse primer (Applied Biosystems, Carlsbad, CA, USA) and $0.2 \mathrm{mM}$ deoxynucleotide triphosphate (dNTPs). Fragments were analysed with ABI PRISM 3100 Genetic Analyser (Applied Biosystems) using LIZ 500 size standard with sizes determined with Genemapper software. Mean haplotype diversity (Schneider et al., 1997) and expected variance (Gordon 1997) were determined for each species and the spatial autocorrelation of samples tested with GENALEX v.6 (Peakall and Smouse, 2001).

\section{Analysis}

Genealogies of the samples were inferred through coalescent analysis (Kingman, 1982) using the application BATWING v.1. 03 (Wilson et al., 2003). The method uses a Bayesian paradigm in which the posterior distribution of $\theta$, being the conditional probability of the prior given the data (haplotypes), is obtained, where $\theta=2 N_{\mathrm{e}} \mu\left(N_{\mathrm{e}}\right.$ being the effective population size and $\mu$ the mutation rate). The number of steps taken to reach coalescence depends on the variability in the data and is measured as $T_{\text {mrca }}$. The application uses linked multilocus haploid data in a step-wise mutation model, which, in the absence of recombination or selection, can be used to derive a genealogical tree (Wilson et al., 2003). Chloroplasts are not subject to recombination, being passed predominantly through the maternal line in angiosperms (Birky, 1995), and because microsatellites are deemed to be non-coding they are not subject to the same selective pressures as functional genes (Provan et al., 2001). The assigned previous distribution for $\theta$ was uniform on the interval $(0,100)$, giving equal probability between these values. Given an upper estimate of chloroplast $\mu$ at $3.2 \times 10^{-5}$ (Provan et al., 1999), $\mathrm{Ne}$ can range from 0 to over 1.5 million, increasing with lower estimates of $\mu$, allowing a diffuse prior. Numerous trials were conducted to assess the influence of different values of $\theta$ and the number of chain runs in the MCMC resulting in the above distribution for $\theta$ and 10000 runs with the first 200 discarded. Determination of satisfactory convergence of the chain and postprocessing was undertaken with the package BOA (Smith, 2005) in TIBCO Spotfire S + 8.1 (http://spotfire. tibco.com/iful/). Posterior distributions were derived for $\theta$ and $T_{\text {mrca }}$ in coalescent units. A lower bound for $T_{\text {mrca }}$ in generations $T_{\text {(gen) }}$ was derived using $\mu$ above and the mean of the posterior of $\theta$, where $T_{\text {(gen) }}=T_{\text {mcra }} \times N e$. Generation times for plants in fire-prone environments are correlated with the fire frequency (Bond and van Wilgen, 1996), in this case 5 years (Williams et al., 2002; Felderhof and Gillieson, 2006), which was used to derive $T_{\text {mrca }}$ in years by simply multiplying $T_{\text {(gen) }}$ by 5 . The justification for this methodology was that a fire event either (a) results in a complete turnover of individuals in the population (that is, Triodia sp.) or (b) resprouting and regeneration by ramets also initiates a periodic somatic mutation event equivalent to that which occurs in meiosis. Consensus trees were produced in Phylip (Felsenstein, 1989) and drawn in FigTree v1.2 (Figure 2) to show
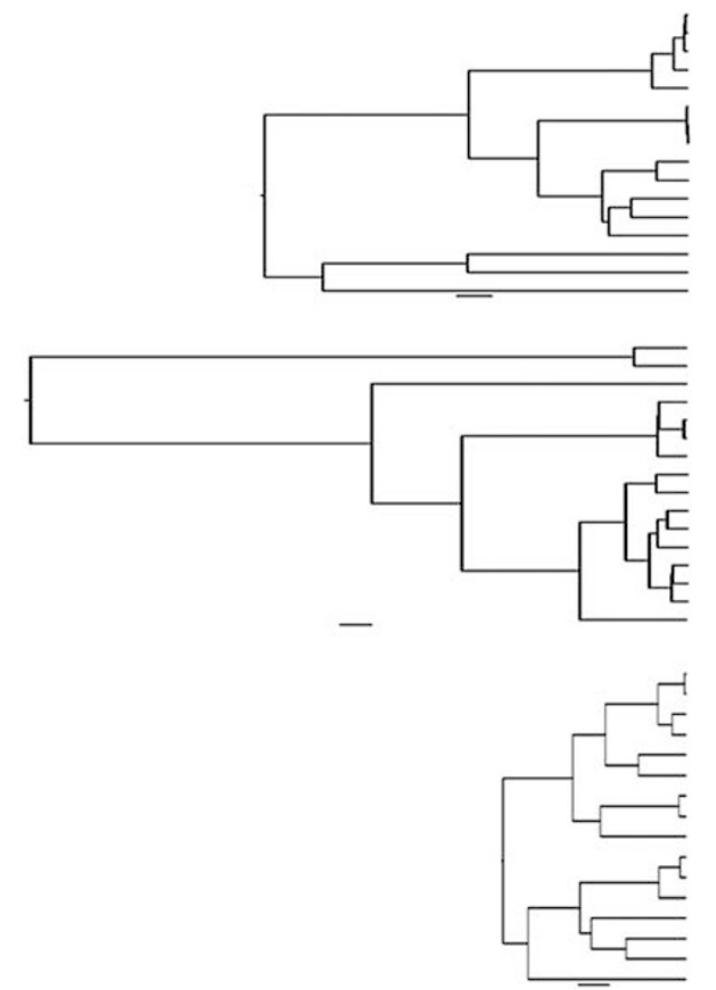

Figure 2 Consensus trees for T. bitextura (top), T. epactia (middle) and Triodia sp. (bottom) scaled to equivalent $T_{\text {mrca }}$. Branch lengths indicate the comparative diversity between adjacent branch tips, with longer branches requiring more mutation steps before they coalesce. Branch tips are the haplotypes of the sampled individuals. Scale bar $=0.1$ mutation steps.

Table 1 The number of alleles per locus and size ranges in base pairs

\begin{tabular}{lcc}
\hline Locus & No. of alleles & Size range, $b p$ \\
\hline atpI/atpH & 5 & $74-80$ \\
atpB/rbcL & 5 & $144-148$ \\
23S-5S ITS & 4 & $196-199$ \\
\hline
\end{tabular}

the topology common to all trees produced in the analysis.

\section{Results}

The size of the microsatellite fragments (Table 1) closely matched those of other grass species reported in Provan et al. (2004) and McGrath et al. (2006) and all species had similar, low levels of mean haplotype diversity and similar expected variance (Triodia sp. $H=0.443$, $V=0.735), T$. bitextura $(H=0.482, V=0.641)$ and T. epactia $(H=0.438, V=0.715)$. No spatial autocorrelation was detected among the samples of any species.

The growth signatures of the coalescent trees (Figure 2) suggest that each of the three samples has had a stable population size since $T_{\text {mrca }}$ (see Kuhner, 2009). However, their genealogies differ in the number of coalescent events, shown by the difference in tree lengths and values of $\theta$ and $T_{\text {mrca }}$ (Figure 2, Table 2). Triodia sp., having the lowest values of $\theta$ and $T_{\text {mrcar }}$ is both the comparatively smallest and youngest population (Figure 3). T. bitextura, with the largest value of $\theta$ and 
Table 2 Posterior mean, median and 95\% probability density interval for theta $(\theta)$ and $T_{\text {mrcar }}$ in coalescent units $(T)$ and generations $\left(T_{(\mathrm{gen})}\right)$, for $T$. bitextura (obligate resprouter), Triodia sp. (obligate seeder) and $T$. epactia (facultative resprouter) using a constant population size model with a uniform $\theta$ prior of $(0,100)$ (see text for details)

\begin{tabular}{lccc}
\hline Species & Mean & Median & $\begin{array}{c}95 \% \text { Probability } \\
\text { density interval }\end{array}$ \\
\hline $\begin{array}{l}\text { T. bitextura } \\
\theta\end{array}$ & 4.20 & 3.76 & $(1.56,9.4)$ \\
$T$ & 1.33 & 1.15 & $(0.45,3.27)$ \\
$T_{\text {(gen) }}$ & 65625 & & $(10969,480281)$ \\
Triodia sp. & & & \\
$\theta$ & 2 & 1.76 & $(0.6,4.76)$ \\
$T$ & 1.30 & 1.13 & $(0.42,3.20)$ \\
$T_{\text {(gen) }}$ & 40625 & & $(3938,238000)$ \\
& & & \\
$T$. epactia & 3.28 & 2.96 & $(1.22,7.25)$ \\
$\theta$ & 2.17 & 1.94 & $(0.75,4.82)$ \\
$T$ & 111212 & & $(14297,546016)$ \\
$T_{\text {(gen) }}$ & & & \\
\hline
\end{tabular}

an equally small $T_{\text {mrca, }}$ indicates a larger population of equally closely related individuals, while $T$. epactia with an intermediate $\theta$ value and the longest $T_{\text {mrca }}$ indicates a comparatively intermediate-sized population with the greatest diversity among individuals of the population. Despite T. bitextura and Triodia sp. having similar values for $T_{\text {mrca }}$, differences in $\theta$ between them result in $T_{(\mathrm{gen})}$ being twice as long for $T$. bitextura. Given a generation time of 5 years, based on the mean fire frequency in this landscape, mean $T_{\text {mrca }}$ values in years for Triodia sp., T. bitextura and T. epactia are 203, 328 and 556k years, respectively.

\section{Discussion}

The study shows that each of the three species, regardless of functional group, have existed in this environment for millennia. The shortest possible $T_{\text {mrca }}$ based on the minimum range of the $95 \%$ probability density interval (PDI), is approximately 19k years for Triodia sp. given a 5-year generation time. The presence of these fire-adapted species, which are totally (Triodia sp., T. epactia) or partially (T. bitextura) reliant on fire to initiate regeneration, reflects the fact that fire is the most common disturbance in this environment and has been a prominent evolutionary force since the Tertiary (Kershaw et al., 2002). The fire history across northern Australia, derived from marine and terrestrial core samples (Moss and Kershaw, 2000; Kershaw et al., 2003), shows an increase in fire activity and fire-tolerant species at approximately 300k years before present $(\mathrm{bp})$ and a subsequent decrease in Eucalyptus and increase in Poaceae at $185 \mathrm{k}$ years bp (Kershaw et al., 2003). While the mean $T_{\text {mrca }}$ of Triodia sp., at 203k years, is similar to this date, T. bitextura and T. epactia, with a mean $T_{\text {mrca }}$ of $328 \mathrm{k}$ and 556k years, respectively, may have been early colonisers into this environment. However, given the large $95 \%$ probability density intervals (Table 2), it is only possible to infer with any certainty that they have all been present, and therefore successful species in this environment, for a significant number of generations.
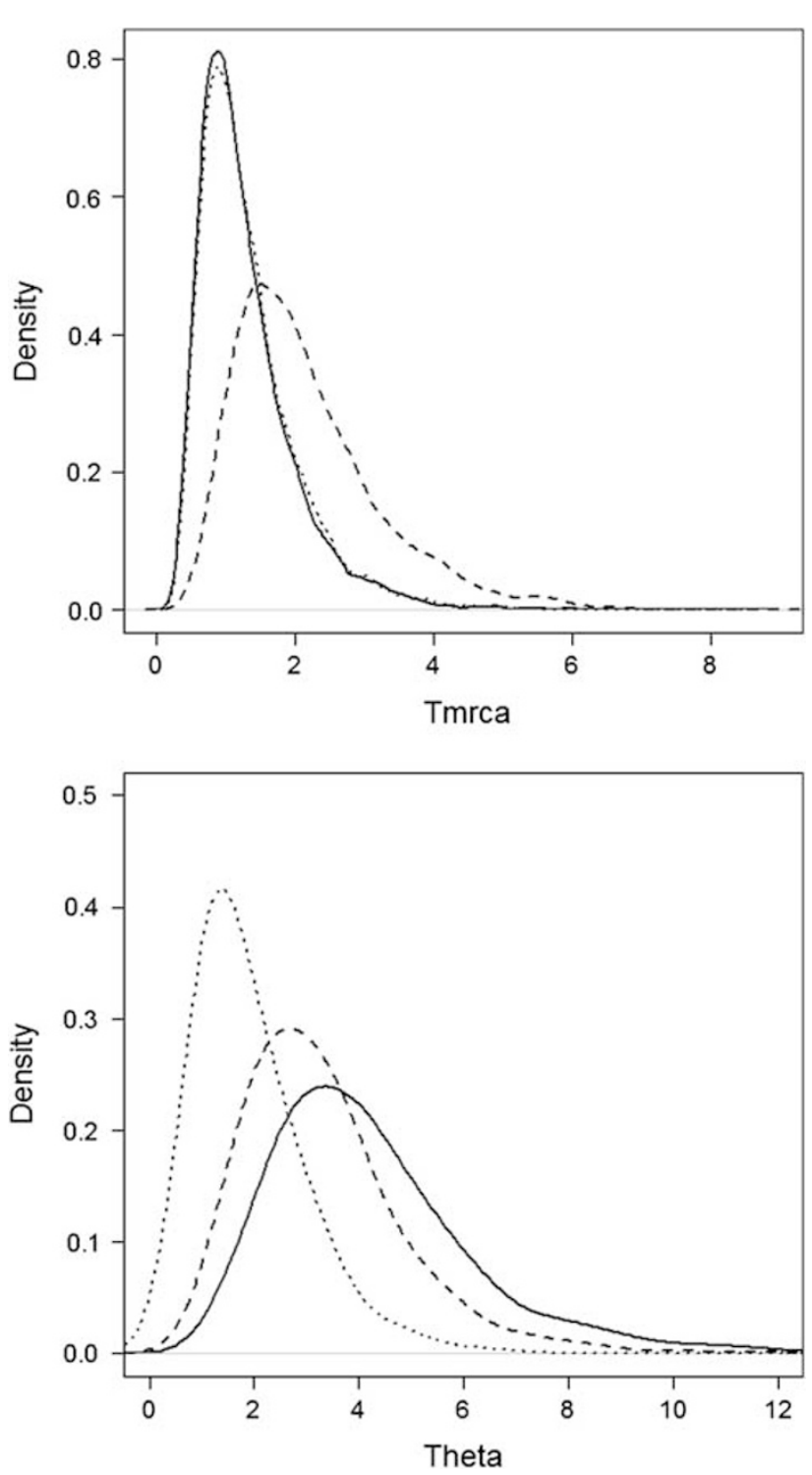

Figure 3 Estimated posterior density plots of Theta and time to most recent common ancestor (Tmrca) for T. bitextura (solid line), Triodia sp. (dotted line) and T. epactia (dashed line). T. bitextura and Triodia sp. are nearly superimposed over each other in Tmrca. See text for definitions of $\theta$ and $T_{\text {mrca. }}$.

Stable population size during $T_{\text {mrca }}$ inferred by the structure of the three genealogical trees (Figure 2), also suggests that T. epactia, and possibly Triodia sp., have been geographically stable during this time. If either population had expanded or reduced their range size during this time, the genealogical trees would infer population growth or decline, owing to serial founder or extinction events at the forward and trailing edge of the species range (Excoffier et al., 2009; McInerny et al., 2009). This was not detected despite T. epactia being sampled at the extreme northern limit of its range and Triodia sp. toward the southern edge of its, comparatively smaller, range. It is not possible to determine the geographical stability of $T$. bitextura during $T_{\text {mrca }}$ because it was not sampled near the edge of its range. The apparent range stability and therefore potential coexistence of T. epactia and Triodia sp., over an area of approx. $2500 \mathrm{~km}^{2}$, for thousands of years indicates that both species have been 

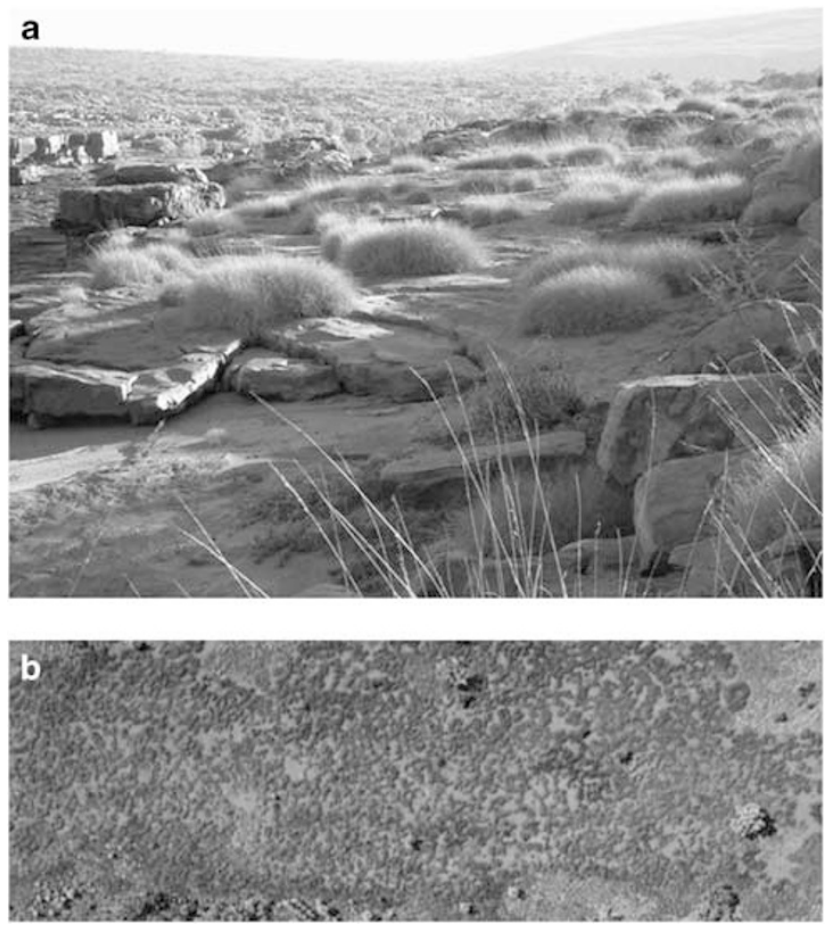

Figure 4 (a) Typical hummock structure common to many Triodia spp. (plants are approximately $1 \mathrm{~m}$ in height and growing on a rock pavement) and (b) the labyrinthine stand structure, seen from the air, showing considerable bare ground between individual plants, in this case growing on sand.

equally resilient to the same fire regime. It is likely that these two species have been in sympatry with T. bitextura for some considerable time also because the expected colonisation rate of this facultative resprouter over such a large area would not be fast.

Coexistence of species with different regeneration responses to fire is hypothesised to be possible because each species utilises different temporal and spatial niche opportunities created by the stochastic nature of the fire regime. The empirical (Thuiller et al., 2007) and theoretical (Miller and Chesson, 2009) evidence to support this is corroborated by modelling that shows species are able to utilise a range of overlapping fire return intervals and scales (Groeneveld et al., 2002). Competition between species limits the potential niche of each, resulting in a single, narrow, realised niche in which all species coexist. Although this has been observed over decadel time scales, this study provides the first evidence that longterm coexistence of these species, from different functional groups, has occurred at least as far back as the late Pleistocene. This negates assumptions that obligate seeding Triodia spp. may be less resilient in northern Australia than resprouting species. While previous research on slow-growing, obligate-seeding Triodia spp. suggested that they would be unlikely to reach a sustainable reproductive output within the short fire return intervals experienced in northern Australia (Craig 1992), this study indicates that obligate seeders can persist in this environment. The obligate seeder Triodia sp. has persisted in this landscape for millennia, possibly owing to its relatively rapid life history and potentially because of stochasticity in the fire regime. Triodia sp. germinates quickly during the first post fire rains and can set seed within a few months of germination (Armstrong, 2011). Reproductive output increases over subsequent seasons, ensuring that a viable seed bank is produced before the mean fire return interval. Such rapid regeneration has been unknown in Triodia spp. until recently (Armstrong, 2008). Variation in the mean fire frequency and stochasticity of fire behaviour could ensure suitable patches are always present within the landscape for the meta-population to survive. Owing to the labyrinthine structure of Triodia spp. stands (Figure 4), in which individual hummocks are separated by bare ground, fires will not spread through the stand unless wind speeds of over $12 \mathrm{~km}$ per $\mathrm{h}$ are attained (Burrows et al., 1991). Fire behaviour is therefore strongly correlated with weather patterns at all scales.

Given the stochasticity in the spatial arrangement of fires in the landscape (see Felderhof, 2007: the fire patchiness paradigm and fire scar maps, Supplementary Appendix), resilience of an obligate seeder, such as Triodia sp., also requires the ability to disperse between suitable patches (Tilman, 2004). This is not required by $T$. epactia or $T$. bitextura, which can recolonise a burnt patch through resprouting. Despite evidence that shows that the majority of seed produced by Triodia basedowii falls close to the mother plant (Westoby et al., 1988), the vast quantity of tiny seeds produced by Triodia sp. must ensure that at least some are dispersed away from the source, most probably by wind and water during rain events in the monsoon.

While it is true that no single fire frequency will favour all species in a community (Pausas and Lloret 2007), it must equally be true that there is a mean frequency, about which there is variation, which enables coexistence. Indeed, even where species from different structural groups coexist, such as Acacia tress and Triodia grasses, the minor perturbations observed at population boundaries, induced by fire, over decadal time scales (Nicholas et al., 2007; Bowman et al., 2008) probably have no long-lasting effect at the community level over much longer time scales. Single or multiple fire events that favour one species may, given enough time, become irrelevant at the community scale as other events favour different species. This study has shown that it is important to consider a wide range of temporal scales when considering the relative resilience of plants from different functional groups to fire. Although there are documented cases of localised extinctions of individual plant species to radically altered fire regimes (RussellSmith et al., 2002), these may represent extreme events and should not be used to generalise about the resilience of particular functional groups. This has not been possible at a global scale (Pausas et al., 2004) and, as this study shows, regional effects, for example, a stable climate, may strongly influence community structure over very long time scales. However, it is important to determine the resilience of regional plant communities to fire, given regimes are changing globally across a range of scales owing to changes in land-use practices (Krawchuk et al., 2009) and altered precipitation patterns both globally (Girardin et al., 2009) and regionally (Hoffmann et al., 2002).

\section{Conflict of interest}

The author declares no conflict of interest. 


\section{Acknowledgements}

This study was supported by the Australian Wildlife Conservancy, the Australian Research Council, Holsworth Wildlife Research Endowment, Stuart Leslie Bird Research Award, Northern Territory Innovation Board and a Wildlife Preservation Society Student Grant. The work would not have been possible without instruction and support from the staff at BioScience North Australia. The paper was improved by comments from Stephen Garnett, Lynda Marshall, Steve Murphy, Sarah Legge, Michelle Hall, Ben Phillips, two anonymous reviewers and the editor.

The funders had no role in the study design, data collection and analysis, decision to publish or preparation of the manuscript, and as such there is no conflict of interest.

\section{References}

Allan GE, Southgate RI (2002). Fire regimes in the spinifex landscapes of Australia. In: Bradstock RA, Williams JE, Gill AM (eds). Flammable Australia. Cambridge University Press: Melbourne,. pp 145-176.

Andersen AN, Cook GD, Corbett LK, Douglas MM, Eager RW, Russell-Smith J et al. (2005). Fire frequency and biodiversity conservation in Australian tropical savannas: implications from the Kapalga fire experiment. Austral Ecol 30: $155-167$.

Armstrong G (2008). Triodia caelestialis (Triodieae: Chloridoideae: Poaceae), a new species from the central Kimberley, Western Australia. J Royal Soc West Aust 91: 313-317.

Armstrong G (2011). Resilience of an obligate seeding grass, Triodia sp. nov. (aff. T. schinzii), (Poaceae) to regular fires in monsoonal north west Australia. Int J Wildland Fire (in press).

Beerling DJ, Osborne CP (2006). The origin of the savanna biome. Global Change Biol 12: 2023-2031.

Birky CW (1995). Uniparental inheritance of mitochondrial and chloroplast genes: mechanisms and evolution. Proc Natl Acad Sci USA 92: 11331-11338.

Bond WJ, van Wilgen BW (1996). Plant demography and fire I. Interval-dependent effects. In: Fire and Plants. Chapman and Hall: Melbourne. pp 52-88.

Bowman DMJS, Boggs GS, Prior LD (2008). Fire maintains an Acacia aneura shrubland-Triodia grassland mosaic in central Australia. J Arid Environ 72: 34-47.

Bradstock RA, Bedward M, Scott J, Keith DA (1996). Simulation of the effect of spatial and temporal variation if fire regimes on the population viability of a Banksia species. Cons Biol 10: 776-784.

Burbidge NT (1943). Ecological succession observed during regeneration of Triodia pungens $\mathrm{R}$. Br. after burning. J Royal Soc West Aust 28: 149-156.

Burrows N, Ward B, Robinson A (1991). Fire behaviour in spinifex fuels on the Gibson Desert Nature Reserve, Western Australia. J Arid Environ 20: 189-204.

Casson NE, Fox JED (1987). The post-fire regeneration responses of Triodia wiseana and T. basedowi. Aust Range J 19: $53-55$.

Chesson P (2000). Mechanisms of maintenance of species diversity. Ann Rev Ecol Syst 31: 343.

Clarke PJ, Dorji K (2008). Are trade-offs in plant resprouting manifested in community seed banks? Ecology 89: 1850-1858.

Craig AB (1992). Aspects of Post-fire Regeneration in Soft Apinifex (Triodia pungens) Communities near Newman, Western Australia. Department Ag West Aust, Department Agriculture Western Australia: Kununurra.

Excoffier L, Matthieu F, Petit R (2009). Genetic consequences of range expansions. Ann Rev Ecol Evol Syst 40: 481-501.
Felderhof L (2007). The fire patchiness paradigm: a case study in northwest Queensland. Unpublished thesis. James Cook University: Townsville.

Felderhof L, Gillieson D (2006). Comparison of fire patterns and fire frequency in two tropical savanna bioregions. Austral Ecol 31: 737-746.

Felsenstein J (1989). PHYLIP-Phylogeny Inference Package (Version 3.2). Cladistics 5: 164-166.

Genries A, Mercier L, Lavoie M, Muller SD, Radakovitch O, Carcaillet C (2009). The effect of fire frequency on local cembra pine populations. Ecol 90: 476-486.

Gordon DM (1997). The genetic structure of Escherichia coli populations in feral house mice. Microbiology 143: 2039-2046.

Girardin MP, Ali AA, Carcaillet C, Mudelsee M, Drobyshev I, Hély C et al. (2009). Heterogeneous response of circumboreal wildfire risk to climate change since the early 1900s. Global Change Biol 15: 2751-2769.

Groeneveld J, Enright NJ, Lamont BB, Wissel C (2002). A spatial model of coexistence among three Banksia species along a topographic gradient in fire-prone shrublands. J Ecol 90: 762-774.

Hoffmann WA (1998). Post-burn reproduction of woody plants in a neotropical savanna: the relative importance of sexual and vegetative reproduction. J Appl Ecol 35: 422-433.

Hoffmann WA, Schroeder W, Jackson RB (2002). Positive feedbacks of fire, climate, and vegetation and the conversion of tropical savanna. Geophys Res Lett 29: 1-4.

Holling CS (1973). Resilience and stability of ecological systems. Ann Rev Ecol Syst 4: 1-23.

Hooper DU, Vitousek PM (1997). The effects of plant composition and diversity on ecosystem processes. Science $\mathbf{2 7 7}$ : 1302-1305.

Kershaw AP, Clark RL, Gill AM, D'Costa DM (2002). A history of fire in Australia. In: Bradstock RA, Williams JE, Gill AM (eds). Flammable Australia. Cambridge University Press: Cambridge.

Kershaw AP, van der Kaars S, Moss PT (2003). Late Quaternary Milankovitch-scale climatic change and variability and its impact on monsoonal Australasia. Marine Geol 201: 81-95.

Kingman JFC (1982). The coalescent. Stoch Proc Apps 13: 235-248.

Krawchuk MA, Moritz MA, Parisien M-A, Van Dorn J, Hayhoe K (2009). Global pyrogeography: the current and future distribution of wildfire. PLOS ONE 4: e5102.

Kuhner MK (2009). Coalescent genealogy samplers: windows into population history. Trends Ecol Evol 24: 86-93.

McGrath S, Hodkinson TR, Salamin N, Barth S (2006). Development and testing of novel chloroplast microsatellite markers for Lolium perenne and other grasses (Poaceae) from de novo sequencing and in silico sequences. Mol Ecol Notes 6: 449-452.

McInerny GJ, Turner JRG, Wong HY, Travis JMJ, Benton TG (2009). How range shifts induced by climate change affect neutral evolution. Proc Royal Soc B 276: 1527-1534.

Miller AD, Chesson P (2009). Coexistence in Disturbance Prone Communities: How a Resistance - Resilience Trade Off Generates Coexistence via the Storage Effect. American Nat 2: E30-E43.

Nicholas AMM, Franklin DC, Bowman DMIS (2007). Characteristics and dynamics of the mulga-spinifex boundaries at Mt Denison Station in Central Australia. Aust I Bot 57: 396-405

Noble J (1989). Fire studies in mallee (Eucalyptus spp.) communities of western New South Wales: the effects of fires applied in different seasons on herbage productivity and their implications for management. Austr J Ecol 14: 169-188.

Moss PT, Kershaw AP (2000). The last glacial cycle from the humid tropics of northeastern Australia: comparison of a 
terrestrial and a marine record. Palaeogeogr Palaeoclimatol Palaeoecol 155: 155-176.

Pausas JG, Lloret F (2007). Spatial and temporal patterns of plant functional types under simulated fire regimes. Int $J$ Wild Fire 16: 484-492.

Pausas JG, Bradstock RA, Keith DA, Keeley JE, The GFN (2004). Plant functional traits in relation to fire in crown-fire ecosystems. Ecology 85: 1085-1100.

Peakall R, Smouse PE (2001). GENALEX version 6 (GENETIC ANALYSIS IN EXCEL): population genetic software for teaching and research. Mol Ecol Notes 6: 288-295.

Prior L, Bowman D, Brook B (2007). Growth and survival of two north Australian relictual tree species, Allosyncarpia ternata (Myrtaceae) and Callitrisintratropica (Cupressaceae). Ecol Res 22: 228-236.

Provan J, Biss PM, McMeel D, Mathews S (2004). Universal primers for the amplification of chloroplast microsatellites in grasses (Poaceae). Mol Ecol Notes 4: 262-264.

Provan J, Powell W, Hollingsworth PM (2001). Chloroplast microsatellites: new tools for studies in plant ecology and evolution. Trends Ecol Evol 16: 142-147.

Provan J, Soranzo N, Wilson NJ, Goldstein DB, Powell W (1999). A low mutation rate for chloroplast microsatellites. Genetics 153: 943-947.

Rice B, Westoby M (1999). Regeneration after fire in Triodia R. Br Aust J Ecol 24: 563-572.

Russell-Smith J, Ryan PG, Cheal DC (2002). Fire regimes and the conservation of sandstone heath in monsoonal northern Australia: frequency, interval, patchiness. Biol Cons 104: 91-106.

Schneider S, Kueffer J, Roessli D, Excoffier L (1997). A Software for Population Genetic Data Analysis. Genetics and Biometry Laboratory, University of Geneva, Switzerland.

Sears ALW, Chesson P (2007). New methods for quantifying the spatial storage effect: an illustration with desert annuals. Ecology 88: 2240-2247.

Shlisky A, Waugh J, Gonzalez P, Manta M, Santoso H, Alvarado E et al. (2007). Fire, Ecosystems and People: Threats and Strategies for Global Biodiversity Conservation. The Nature Conservancy: Arlington, VA.

Smith BJ (2005). BOA: Bayesian Output Analysis Program, Version 1.1.4. Department of Biostatistics, University of Iowa College of Public Health, Iowa. Available from http://www. publichealth.uiowa.edu/boa/. In.

Thuiller W, Slingsby JA, Privett SDJ, Cowling RM (2007). Stochastic species turnover and stable coexistence in a species-rich, fire-prone plant community. PLOS ONE 2: e938.

Tilman D (2004). Niche tradeoffs, neutrality and community structure: a stochastic theory of resource competition, invasion and community assembly. Proc Natl Acad Sci USA 101: 10854-10861.

Ustin SL, Gamon JA (2010). Remote sensing of plant functional types. New Phytol 186: 795-816.

Verdu M (2000). Ecological and evolutionary differences between Mediterranean seeders and resprouters. J Veg Sci 11: $265-268$.

Wells G (1999). Biology and Restoration Ecology of Spinifex Grasses (Plectrachne and Triodia spp.) with Special Reference to the Argyle Diamond Mines (Western Australia).Unpublished Thesis. University of Western Australia: Perth.

Westoby M, Rice B, Griffin G, Friedel M (1988). The soil seed bank of Triodia basedowii in relation to time since fire. Aust J Ecol 13: 161-169.

Williams PR, Congdon RA, Grice AC, Clarke PJ (2003). Effect of fire regime on plant abundance in a tropical eucalypt savanna of north-eastern Australia. Austral Ecol 28: 327-338.

Williams RJ, Griffiths AD, Allen GE (2002). Fire regimes and biodiversity in the savannas of northern Australia. In: Bradstock RA, Williams JE, Gill AM (eds). Flammable Australia. Cambridge University Press: Melbourne, pp 281-304.

Wilson I, Weale M, Balding D (2003). Inferences from DNA data: population histories, evolutionary processes and forensic match probabilities. J Royal Stat Soc A Stat Soc 166: 155-188.

Supplementary Information accompanies the paper on Heredity website (http://www.nature.com/hdy) 